\title{
A criança, a escrita e a leitura: sugestões para a ação
}

\author{
Geraldina Porto Witter \\ PUC-Campinas
}

As sugestões aqui arroladas decorrem de pesquisas, as quais evidenciam a eficiência das mesmas. Elas servem a pais, professores e profissionais que atuam na área de prevenção e de recuperação da leitura e da escrita. Como pessoa responsável pela formação de leitores é necessário estar atento ao próprio comportamento como leitor, à bibliografia sobre literatura infanto-juvenil, sobre motivação e tecnologias úteis à melhoria da leitura e ao êxito enquanto leitor. As sugestões aqui apresentadas decorrem de uma vivência de mais de 40 anos trabalhando com a leitura e com leitores, da prática, da pesquisa e de muita leitura. Espera-se estar repassando parte desta vivência, com tópicos, que sugiram ações para psicólogos, pais, professores, fonoaudiólogos, bibliotecários, para todos que queiram ajudar a formar leitores.

1. Enquanto a criança é alimentada (desde o recém-nascido) converse pausadamente com ela, à medida que ela cresce, aproveite para ir ensinando o nome dos alimentos, dos objetivos usados na ocasião, aos poucos introduza informações sobre como são feitos os alimentos, de onde eles surgem, até sobre seu custo.

2. Enquanto dá banho na criança (desde o recém-nascido) converse pausadamente com ela, ao tocar cada parte do corpo dela diga o nome; quando ela já tiver alguma produção peça que repita; que diga o nome (quando já souber) para manutenção ou retenção do aprendido; use jogos: "Agora vou pegar ou lavar o.. " (dar pistas apontando ou olhando em direção e esperar que ela diga o nome, se não souber, diga-o, se errar, diga "é... ".

3. Enquanto veste a criança dizer o nome (e, mais tarde, as cores) das peças de roupa; quando já souber falar, pedir que repita, fazer jogos de adivinhação (o que é que se põe no pé? Depois da calcinha a gente põe...; De que cor é a blusa que tenho na mão?).

4. Quando sair com a criança (a pé ou de carro, especialmente a ida-volta à escola já foram bem pesquisadas) é preciso aproveitar para falar com ela, mostrar coisas, ensinar-lhe os nomes das coisas, pedir que diga os nomes. Se estiver no carro (ou ônibus escolar) fazer o mesmo, cantar ou recitar ritmicamente.

\section{Desenvolver conversação}

a. Quando no "shopping", supermercado, drogaria etc. conversar com a criança sobre o que está comprando, porque está comprando, quando irá usar, quanto custa; veja o que ela gostaria de comprar.

b. Quando estiver cozinhando converse com a criança sobre o que está fazendo, a ordem em que faz, sobre o que ela gosta de comer, como é feito seu prato predileto (fale e mostre como se faz, tantas vezes quantas forem necessárias).

c. Antes de sair para um passeio ou excursão (a pé ou de condução) converse com a criança 
sobre onde vão, o que irão fazer, o que irão ver; quando chegar ao local recorde com ela, diga o nome e o que mais a interessar sobre o que estão vendo ou fazendo; faça jogos verbais e outros durante o passeio (lá vem um barquinho carregadinho de...; o primeiro carro que vem é...).

d. Estabeleça um horário para contar história para e com a criança (na escola pode ser logo após o recreio, como período de acomodação; no lar o horário que for mais conveniente, para muitos e na hora de dormir). $\mathrm{O}$ adulto ou a criança começa, outro continua (2 a três orações cada), alternando um com outro até acabar a história (invente histórias, mas elas devem ter sempre um fim). Faça da leitura uma rotina agradável, um momento de emoção e de surpresa.

e. Estabeleça um dia por semana para jogos (em casa e na escola) de memória, de adivinhação, de alfabeto, de números.

f. Pedir que a criança conte como foi seu dia (na casa, na escola).

\section{Ler para a criança}

É necessário ler diariamente para a criança, aumentando gradualmente o tempo de leitura (de alguns minutos para o recém-nascido, até 20 minutos para a criança de 4 a 5 anos, até meia hora para as mais velhas (excepcionais ou não) que ainda não tenham o domínio da leitura. Pode estabelecer um horário (na escola pode alternar um dia lê, outro conta história, após o recreio (este horário não é o da "aula" de leitura), quando julgar conveniente (após o lanche, ou antes da hora de dormir) ou simplesmente no momento que parecer mais conveniente. O importante é ler, ler, ler muito para a criança, mas sem pressioná-la.

São meios para tornar a leitura agradável e educativa:

a. conhecer a amplitude de atenção da criança e não ir além dela;

b. conhecer os interesses da criança para escolher material para leitura, com ênfase na discussão do texto e da ilustração (se for o caso), evitando perguntas de certo ou errado;

c. fazer questões sobre a história, aceitar os pensamentos e proposições da criança para outras direções na trama da história, evitando perguntas de certo e errado, mas verificar se houve entendimento sobre a mensagem do autor (Ex.: sobre o que será a história que vou ler? (lê uma parte). Como será que vai acabar?... E agora que vai acontecer? Como gostaria que a história acabasse?

d. permita que a criança "leia" com ou para você quando já conhece bem a história.

\section{Quando ler para a criança}

Sempre que possível, leia para a criança, quanto mais melhor, escolher situações particularmente agradáveis para a criança, usar um contexto lúdico é útil.

a. Ao amamentar, dar a mamadeira, ou lanche: recitar poesias infantis, ler e contar histórias.

b. Quando a criança estiver irrequieta, com medo, nervosa, tentar acalmá-la lendo alguma história engraçada ou cantando uma música infantil (ritmos marcado e repetitivos).

c. Aproveitar todos os momentos tranqüilos e transformar a própria leitura em um momento tranqüilo.

d. Antes de ir ao médico, ao dentista, ou de ir tomar vacina ler para a criança ou com ela histórias que mostrem estes profissionais em ação.

e. Ter sempre à mão um livro para ler para a criança em salas de espera (de médicos, rodoviárias, aeroportos, estações de trem). 
f. Antes e após ver um programa de TV baseado em um livro, ler e discutir o próprio com a criança ou uma obra similar. Por exemplo, viu um desenho sobre o Patinho Feio, ler o livro com a criança.

\section{Permitir que a criança leia}

A seqüência começa por aprender a virar a página, "ler" através das figuras, "ler" o texto. Elogie cada progresso e atitude, inclusive quando, sem saber ler a criança "faz de conta" que está lendo. Estimule cada tentativa e interesse pela leitura.

a. Coloque cartazes e livros coloridos (de pano ou cartão) no berço e no cercado do bebê (substituí-los semanalmente, usar ciclicamente o que ficou numa semana é guardado por uma semana ou duas e depois é recolocado).

b. Organize um espaço para a criança ter sua própria biblioteca (estante de classe).

c. A partir dos 3 anos levar a criança para a hora do conto ou da história na biblioteca pública ou escolar; quando ela já estiver lendo viabilizar que participe de outras atividades da biblioteca (planejar com o bibliotecário).

d. Faça o registro da criança em alguma biblioteca infanto-juvenil (começar aos 3 anos de idade e encoraje-a a escolher e a retirar livros para ler em casa (planejar com o bibliotecário) só ou com os pais.

e. Recorra a livros que têm fita ou disco gravados para serem usados concomitantemente (multi-meios).

f. Ponha livros em vários lugares em casa para que a criança possa achá-los e lê-los a qualquer momento.

g. Assine revistas infantis para seus filhos ou solicite para à bibliotecária para comprá-los e por à disposição das crianças.

h. Converse com a criança sobre o que ela leu, ouça seus comentários, fique atento a opinião, que manifeste procure conhecê-la, como pessoa através de suas leituras e comentários.

i. À medida que a criança for dominando a leitura reveze-se com ela na leitura.

\section{Permitir que a criança Escreva}

Se a criança vive em uma sociedade que usa a escrita ela pode começar a aprender a escrever aos 18 meses, ou mesmo antes dependendo da estimulação ambiental e de seu repertório básico. Começa com riscos e formas circulares, abrangendo todo o papel, depois passa a organizá-los no espaço, seguem-se garatujas e riscos já acompanhando o sentido (vertical ou horizontal, esquerdadireita, direita-esquerda) dos modelos de escrita a que foi exposta. A habilidade de escrita requer anos para se desenvolver, é preciso respeitar o ritmo e a produção da criança em cada fase. É preciso valorizar qualquer produção da criança, fornecer-lhe oportunidades diárias e orientá-la para estar sempre evoluindo. Para auxiliar a criança a desenvolver a escrita é útil:

a. Escrever - seja um exemplo como escritor, escreva, mostre como e quando usa a escrita, escreva para ela, faça listas de coisas que ela goste.

b. Facilidade de Materiais - facilite à criança ter acesso a materiais para escrita (papel colorido, lápis, blocos de papel, máquina de escrever, areia, alimentos com letrinhas e, se possível computador em casa e na escola, desde o pré, 2 anos já é uma boa idade para introduzir o computador). 
c. Celebre a autoria da criança - peça que leia o que escreve, fale-lhe sobre a escrita, desenhos, letras, signos; encoraje-a a conversar sobre desenhos e histórias e, responda suas perguntas, seja um bom ouvinte.

d. Valorize a escrita da criança - exponha desenhos e escritos seus na cozinha, no quarto, no quadro de avisos, em varais na classe etc. Organize os melhores em álbuns. Guarde seus primeiros esforços para desenhar ou escrever, mostre os progressos que fez.

e. Ler para a criança pelo menos 15 minutos por dia ajuda seu desenvolvimento da escrita.

f. Conte histórias clássicas da literatura infantil e outras sobre a vida diária, encorajando-a recontar, modificar e a desenhar combinando história e texto.

g. Encoraje a criança a incluir a escrita como atividade diária tanto em casa como na escola, como tarefa e como lazer.

h. Dê tempo para a criança aprender, apresente modelos corretos, sem destruir ou considerar "erros" que são apenas típicos de uma fase de seu desenvolvimento, mas ajude-a a superar suas limitações e a ter desempenho cada vez mais correto.

i. Responda a todas as perguntas da criança sobre escrita e leitura quando não souber mostre que irá (faça-a ver isto) procurar nos livros a resposta.

j. Use jogos de letras para a criança brincar (desde os 2 anos) vá ensinando aos poucos os nomes das letras (associar com nomes dela, pais, irmãos, avós, colegas) aos poucos, brincando, vá ensinando a juntá-las, escrever, copiar, ler recados).

$\mathrm{k}$. Ponha em letras de formas maiúsculas em um canto do papel o nome dela (desde a $1^{\mathrm{a}}$ folha que receber).

I. Quando "desenhar" ou "escrever" pergunte o que é e escreva em letra de forma em maiúscula o que ela disser ao lado do "desenho " ou "escrita".

\section{Lembrar-se sempre que pais e professores são modelos de leitores e de escritores}

a. Em lugar tranqüilo leia, escreva e cante para e com a criança (desde recém-nascida).

b. Quando passear em parques e jardins leve material para ler, pintar, e cante com a criança.

c. Quando um brinquedo ou jogo tiver instruções ou regras e a criança não souber ler, leia para ela mostrando onde a matéria está escrita (repita a cada vez que for usar o jogo ou o brinquedo).

d. Estabeleça uma hora de leitura em família, (leitura individual ou coletiva), com duração e regras estabelecidas em conjunto, de acordo com as necessidades da família (fazer o mesmo em classe) contar com um período de tempo para comentar as leituras.

e. Comentar com os filhos e alunos o que tiver lido de interessante (jornais, revistas, romances).

f. Explique à criança que precisa de algum tempo de silêncio para que você possa ler, solicitando que faça o mesmo por alguns minutos.

g. Quando não tiver material em casa ou em classe para responder às questões da criança vá com ela à biblioteca para achar um livro sobre o assunto.

h. Oriente a escolha de livros na biblioteca.

i. Leve a criança freqüentemente às livrarias e ajude-a a conhecer o ambiente e a escolher material. Há livrarias com espaço e atenção especial para crianças. Freqüente-as com seus filhos, netos, alunos. 
Finalmente, esteja sempre atento ao seu comportamento como modelo de leitor e ao comportamento do leitor em formação. Melhorando como leitor estará sendo um melhor modelo e ajudando o outro a melhorar. 